\title{
Whole-genome sequencing reveals a deeper history of dynamic biotic complexity along North America's North Pacific Coast
}

\author{
Jocelyn Colella ${ }^{1}$, Tianying Lan $^{2}$, Sandra Talbot ${ }^{3}$, Charlotte Lindqvist ${ }^{4}$, and Joseph Cook $^{1}$ \\ ${ }^{1}$ University of New Mexico \\ ${ }^{2}$ State University of New York at Buffalo \\ ${ }^{3}$ USGS Anchorage \\ ${ }^{4}$ University at Buffalo (SUNY)
}

May 5, 2020

\begin{abstract}
Shared phylogenetic breaks across taxa, syntopic clusters of endemics, and paleogeographic reconstruction of isostatic and vegetation change over time suggest the existence of one or more ice-free glacial refugia off of North America's North Pacific Coast. An incomplete fossil record, however, creates uncertainty over which species persisted in hypothesized refugia, obscuring interpretation of the timing, potential duration, and surrounding paleoenvironments. We use whole-genome resequencing to assess the historical biogeography of these complex northern landscapes that consist of multiple coastal archipelagos and mountain ranges. Discovery of distinct insular and continental clades within Pacific martens (M. caurina) is consistent with previous morphometric and parasitological studies and also with the Coastal Refugium Hypothesis, thereby supporting the persistence of diverse, potentially forested refugial communities along the western edges of the Alexander Archipelago. We found no evidence of admixture on islands that received translocations of American pine martens (M. americana) in the mid 1900s, but we detected introgression in two geographically distinct zones of secondary contact. Evidence of early-generational hybrids across multiple hybrid zones, each backcrossed with M. americana, is consistent with a history of genetic dilution of M. caurina through outbreeding with M. americana. Into the future, these hybrid zones will serve as iterative tests for the outcome of admixture, providing instructive natural experiments for forecasting outcomes of proactive measures such as genetic rescue by natural resource managers.
\end{abstract}

\section{INTRODUCTION}

Centers of endemism and geographically clustered hybrid zones are hypothesized to be the legacy of species persistence through the Pleistocene in multiple ice-free glacial refugia followed by population expansion and contact (Hultén 1937; Heusser 1989; Heaton \& Grady 2003; Swenson \& Howard 2005). Isostatic adjustment and lower sea-levels (Mann 1986) are credited with exposing areas of the continental shelf along North America's North Pacific Coast (NPC) and providing terrestrial sanctuary for insular and coastal species displaced by the expanding Cordilleran and Laurentide ice sheets (Heaton et al. 1996; Hewitt 2000; Lacourse et al. 2003; Mathewes \& Clague 2017). Multiple refugia are hypothesized within southeast Alaska's contemporary Alexander Archipelago (e.g., Baranof, Chichagof, Dall, Heceta, and Prince of Wales islands; Foster 1965; Fedorov \& Stenseth 2002; Carrara et al. 2003, 2007; Ager 2019) and British Columbia's Haida Gwaii Archipelago and surrounding areas (Heusser 1989; Mathewes \& Clague 2017). Ice-free coastal refugia may have also played an integral role in human colonization of the Americas by opening a maritime migration corridor. New evidence shows the Pacific Northwest was inhabited by humans as early as $>15-16$ thousand years ago (kya; Devièseet al. 2018; Davis et al. 2019) and the Alexander Archipelago at least > 10 kya, but likely more than 13 kya (Dixon et al. 2014; Carlson \& Baichtal 2015; Lesnek et al. 2018; Mackie et al. 2018; McLaren et al. 2018), potentially predating the opening of an ice-free migration corridor through 
central Alberta, Canada ( $<=14.8$ kya; Margold et al. 2019). An incomplete fossil record, however, creates uncertainty over which species persisted in hypothesized refugia, obscuring interpretation of their duration and paleoenvironments. Unlike humans with access to rudimentary sea-faring technologies (Erlandson et al. 2007), other coastal refugial mammals would have been essentially isolated from mainland populations, leading to a cessation in gene flow and divergence over time (Hewitt 2000). As such, the genomes of refugial descendants can provide clues to whether populations or species diverged in refugial isolation. Predicted variation includes high genetic differentiation from other refugial populations and the abundance of endemic or ancestral alleles, low genetic diversity as a consequences of small population sizes and genetic drift, and less spatial structure relative to recently colonized populations (Hewitt 2000).

In contrast to glacial isolation, post-glacial population expansion from multiple refugia can lead to secondary contact and the formation of hybrid zones between previously isolated taxa (Hewitt 2000; Swenson \& Howard 2005). The rapid climatic oscillations of the Pleistocene (Williams 1998) led to recurrent opportunities for contact and gene flow between incompletely diverged taxa (Hewitt 2000, 2003). The consequences of genetic exchange are complex and range from homogenization to hybrid speciation (Arnold 1997; Harrison \& Harrison 1993; Genovart 2009; Abbott et al. 2016), depending on the level of differentiation, but they can now be examined in detail using whole-genome sequences (Twyford \& Ennos 2012).

North American martens are relatively small meso-carnivores, hypothesized to have diverged in at least two independent glacial refugia south of the Laurentide ice sheet (Stone et al. 2002): one refugium east of the Rocky Mountains or Mississippi River drainage giving rise to American pine martens (Martes americana, Turton 1806) and another to the west, presumably the cradle for Pacific martens (Martes caurina, Merriam 1890). However, the disjunct contemporary range of Pacific martens and occurrence of two natural hybrid zones between these species one occurring on near-coastal islands (Kuiu and Kupreanof, AK) along the NPC and another in the northern Rocky Mountains (Fig. 1) suggest Pacific martens may have a deeper evolutionary history along the NPC than previously thought (Pauli et al. 2015). The widespread coast-tocoast boreal distribution of $M$. americana directly contrasts with the fragmented distribution of $M$. caurina, found along the Pacific coast (CA, OR, WA), mountaintops of the American Southwest (NM, CO, UT) and northward into Montana and Idaho, and four islands within the putative refugial archipelagos of the NPC: Graham, Moresby, Kuiu, and Admiralty islands.

In addition to two natural hybrid zones, a series of intentional wildlife translocations in the mid-1900s introduced $M$. americanato multiple NPC islands without prior knowledge of the native marten species in the region (Powell et al. 2012). While these introductions may complicate the interpretation of genomic signals from this region, they also provide a framework for interpreting the consequence of natural versus anthropogenically-mediated gene flow on the evolution and persistence of species. Accidental introductions (Fenichel et al. 2008; Weber et al. 2017) or intentional, motivated by economics (McNeely 2001; Fenichel et al. 2008; Powell et al. 2012), public safety (Massei et al. 2010) or conservation (Powell et al. 2012), are increasingly common and can result in unanticipated consequences, including hybridization with native species (Todesco et al. 2016) and exchange of parasites (Prenter et al. 2004) with unknown evolutionary outcomes. Genetic management techniques, including genetic rescue (Whiteley et al.2015) or gene tweaking (Thomas et al. 2013), are increasingly proposed as viable mechanisms to boost diversity in small inbred populations. Application of these techniques can be informed through investigations of existing hybrid zones and historical wildlife translocations which can cumulatively inform a predictive framework for anticipating the evolutionary consequences of genetic exchange. In martens, hybridization may disproportionately impact Pacific martens through genetic dilution from outbreeding (Colella et al. 2018a). Low genetic variation in certain insular populations of M. caurina (Stone et al. 2002; Small et al. 2003) has led to further concerns over their persistence, which may be exacerbated by ongoing harvest of forests and extraction of minerals on those islands (Durbin 1999; USDA 2018).

We use whole-genome resequencing data to refine our understanding of the biogeographic history of NPC martens and place these results within the context of the Coastal Refugium Hypothesis (CRH; Heusser 1989; Scudder \& Gessler 1989; Heaton et al. 1996; Demboski et al. 1999; Sawyer et al. 2019). With increased 
molecular resolution, we explore the evolutionary consequences of introgression in New WorldMartes to further inform natural resource management initiatives. We examine the distribution of geographic variation and estimate the timing and directionality of introgression to assess the role of natural hybridization, historic wildlife translocations, natural colonization events, and glacial cycling in shaping the evolution of New World martens.

\section{MATERIALS AND METHODS}

\section{Genome sequencing, assembly, and post-processing}

We generated 11 whole-genome sequences representing both New World marten species, including individuals collected in both known hybrid zones (Kuiu [KUI] and the northern Rocky Mountains [MTX]) and multiple translocated islands (Prince of Wales Island, POW; Chichagof Island, CHI), with an Old World sable (Martes zibellina ) included as an outgroup (Table 1). Sequences were generated on an Illumina HiSeq $\mathrm{X}$ through the Beijing Genomics Institute (BGI Americas, Philadelphia, PA, USA) and NextSeq 500 through the Molecular Biology Facility at the University of New Mexico. Sampling was based on previous genetic (Dawsonet al. 2017; Colella et al. 2018a) and morphological analyses (Colella et al. 2018b) that helped define species limits and refine hybrid zone locations through the identification of mixed mitochondrial and nuclear haplotypes. Subsamples of liver tissue were loaned from the University of New Mexico's Museum of Southwestern Biology (MSB) and the Burke Museum at the University of Washington (UWBM). DNA extractions followed a DNeasy Blood and Tissue Kit (Qiagen, Venlo, The Netherlands) protocol. Our assembly pipeline followed Colellaet al. (2018c). Read quality was examined using FastQC (Andrews 2010) and adapter sequences and sex chromosomes removed by excluding those scaffolds from the reference (Trimmomatic v0.33; Bolger et al. 2014). The Burrows-Wheeler aligner (BWA, Li \& Durbin 2010) was used to map reads to the domestic ferret genome (Mustela putorius furo ; Peng et al. 2014) and an additional BWA iteration extracted mitochondrial genomes using the same reference. Final depth of coverage ranged from 19 to 30X (Table 1). PCR duplicates were removed using Picard v1.9 (MarkDuplicates; http://broadinstitute.github.io/picard/) and nuclear and mitochondrial consensus sequences called using SAMtools (mpileup; Li et al.2009). Single nucleotide polymorphisms (SNPs) were called with the Genomic Analysis Toolkit (GATK, Haplotypecaller; McKenna et al.2010) for all North American marten and again against the M. zibellina outgroup. SNPs were filtered (Supplemental Information1) by minimum depth (minDP $=2$, set to $1 / 3^{\text {rd }}$ the coverage of our lowest coverage sample, as recommended for PSMC analyses; Li \& Durbin 2011), genotype quality (minGQ $=30)$, minimum minor allele frequency $(\mathrm{MAF}=0.1)$, and scaffold size $(1 \mathrm{Mb})$. Private alleles and indels were removed using VCFtools (Danecek et al. 2011). A MAF of 0.1 removed singletons (e.g., individual-specific, rare mutations), which are not informative about allelic overlap among populations, to reduced potential sequencing errors more common in lower coverage genomes. Format conversions (vcf, ped, bed) were conducted in PLINK (Purcell et al. 2007). Missing data were removed (-max-missing, VCFtools) based on analysis specifications. Variants were spaced (1 per 100bp window) to account for linkage disequilibrium and sorted into 46 'pseudo-chromosomes' to enable the application of human-specific analyses to a non-model system with only 38 chromosomes using custom python scripts available online at https://github.com/jpcolella/.

\section{Assessing genomic differentiation}

We generated maximum-likelihood phylogenies for complete mitochondrial genomes and autosomal SNPs, with and without the inclusion of an outgroup, using RAxML (GTRCAT model, 10,000 bootstrap replicates, random starting seed; Stamatakis 2014). It should be noted that phylogeny inference using highly variable data (e.g., SNPs) can induce acquisition bias resulting in longer branch lengths (Leaché et al. 2015). Phylogenies were visualized in FigTree v1.2.2 (http://tree.bio.ed.ac.uk/software/figtree/).

Principal component analyses (PCA) were run and visualized using the SNPrelate (Zheng et al. 2012) R v3.3.4 library ( $\mathrm{R}$ Development Core Team 2008). Diversity statistics $\left(F_{I S}, \mathrm{~F}_{\mathrm{ST}}, \mathrm{F}_{\mathrm{S}}\right.$ or relatedness2 statistics, nucleotide diversity $(\pi)$, and Tajima's $D$ ) were calculated in VCFtools (Commands: -het, -weir-fst-pop, -relatedness2, -window-pi, -TajimaD, respectively), with $\pi$ and Dcalculated in $100 \mathrm{bp}$ window intervals. F2 statistics were generated from the compute_moment_stats and compute_most_additive_trees functions in 
MixMapper (Lipson et al. 2013) with 1000 bootstraps and SNP blocks of 100 (1 per 100 bp) in MatLab 2018 (The MathWorks, Inc., Natick, Massachusetts, USA).

\section{Introgression analyses}

For ADMIXTURE (Alexander et al. 2009) analyses, sites with $>80 \%$ missing data were removed. The greatest delta $(\Delta)$ in cross-validation $(\mathrm{cv})$ score identified the most appropriate number of populations $(\mathrm{K})$ by iteratively leaving a sample out and reexamining the partitioning of genetic structure among the remaining samples. ADMIXTURE results were visualized in $\mathrm{R}$ v3.3.4. Populations identified by ADMIXTURE were used in $F$ - statistics.

$F$-statistics were run in AdmixTools (Patterson et al.2012) using M. zibellina as an outgroup. F3- statistics [Target: Source-1, Source-2] explicitly test for admixture (3PopTest in AdmixTools) and considered all permutations where Source-1, Source-2, and the Target samples came from different populations. While a significantly negative F3 score $(\mathrm{Z}<5)$ denotes admixture in the Target sample, a positive F3 value does not necessarily indicate the absence of admixture (Peter 2016). To determine the generational status (e.g., F1, F2, B1, B2, etc.) of each identified hybrid individual, we use R code available from Lavretsky et al.(2016) to simulate multi-generational hybrids based on unadmixed M. americana ('POP1') and M. caurina ('POP2'). We contrasted admixture proportions of empirical hybrids against proportions output for simulated multigenerational hybrids to estimate generational status. Last, Treemix (Pickrell \& Pritchard 2012) was used to infer historical relationships among populations with 2, 3 or 4 mixture events.

To characterize the backcrossing history of each hybrid sample, we usedF4- statistics, similar to D-statistics or ABBA/BABA (Kulathinalet al. 2009; Green et al. 2010; Durand et al.2011), in AdmixTools with blockjackknifing accommodating non-independence between loci. Although $F$-statistics alone cannot deduce the direction of gene flow in a system, admixture graph fitting can test whether a proposed evolutionary model fits the data well (Lipson et al. 2013; Martin et al. 2015). AdmixtureGraph (Mailund et al. 2016) iteratively fit hybrid individuals into two non-admixed tree topologies (RAxML topology and the RAxML topology collapsed into $\mathrm{K}=6$ populations; Supplemental Information 2-3) by estimating the minimal error placement from $F 4$ results. We tested all $F 4$ population permutations excluding hybrids identified through F3- statistics. We then tested hybrids against individuals from 'pure' populations (e.g., F4 (Outgroup, Hybrid; continentalamericana, insular caurina )) to decipher the backcrossing histories of hybrid samples and characterize patterns of gene flow across populations. F4 -statistics [W, X ; Y, Z] are negative (Z-score [?] -5) if there is more allelic overlap between $\mathrm{X}$ and $\mathrm{Y}$ than between $\mathrm{X}$ and $\mathrm{Z}$, and positive (Z score [?] 5) if there has been more recent allele sharing between $\mathrm{X}$ and $\mathrm{Z}$ than between $\mathrm{X}$ and $\mathrm{Y}$. To estimate the timing of introgressive events, we converted drift unit branch lengths $(D)$ output from MixMapper to absolute time (years) using the formula $D$ [?] 1- $\mathrm{e}^{-\mathrm{t} / 2 \mathrm{Ne}}$ (solved for tgenerations; Puckett et al. 2015) and a generation time of 5 years (Buskirk et al. 2012). Small sample sizes and the absence of a Martes linkage map prevents linkage disequilibrium-based estimates of $\mathrm{N}_{\mathrm{e}}$ and more refined dating of admixture events.

\section{Historical demography}

PSMC (Li \& Durbin 2011) was used on consensus genomic sequence data to characterize historical demography by examining heterozygosity densities in 100bp sliding windows across the genome. PSMC was run twice for each individual, once utilizing all mapped sequence data and again on data down-sampled to 20X coverage (near the lowest coverage sample) using the DownsampleSam tool (Picard). Results were scaled by a general mammalian mutation rate $\left(2.2 \times 10^{\wedge}-9\right.$ per base pair per year; Kumar \& Subramanian 2002) and marten generation time (5 years), resulting in distributions of effective population size $\left(\mathrm{N}_{\mathrm{e}}\right)$ through time. One hundred PSMC bootstrap replicates were performed and plotted for both full-coverage and downsampled data to confirm consistent distributional shapes and enable comparison across individuals, as PSMC is sensitive to variation in coverage depth (ideal coverage >18X; Nadachowska-Brzyska et al. 2016).

\section{RESULTS}

Genomic differentiation 
Mitochondrial and nuclear phylogenies (Fig. 2d) show strong support for two reciprocally monophyletic species: M. americana and M. caurina. Both trees also show support for an insular M. caurinaclade (QCI, $\mathrm{ADM})$. The placement of the two continental M. caurina(COL, PNW) differed in the two phylogenies, but they were strongly supported as distinct from the insular $M$. caurina, suggesting substantial genomic divergence between continental and insular M. caurina. Two individuals (KUI, MTX) exhibited cytonuclear discordance. PCA results (Fig. 2a-c) are consistent with our nuclear phylogeny, demonstrating substantial divergence not only between New WorldMartes species ( $\mathrm{PC} 1=46 \%$; Fig. 2b), but also between insular and continental populations of $M$. caurina ( $\mathrm{PC} 1=39 \%$; Fig. 2c). Within M. caurina, PC2 also separates mainland M. caurinapopulations (COL, PNW) and accounts for a notable $34 \%$ of the variation. PCA plots (Fig. 2a-c) highlight the intermediacy of putative hybrid individuals (KUI, MTX) and also their distinction from each other.

The inbreeding coefficient, $\mathrm{F}_{\text {IS }}$, is highest for insular $M$. caurina : 0.89 for ADM and 0.77 for QCI (Supplemental Information 4). Mainland M. caurina also exhibit high $\mathrm{F}_{\mathrm{IS}}, 0.65$ for PNW and 0.62 for COL, followed by populations of $M$. americana. CHI has the lowest $\mathrm{F}_{\mathrm{IS}}$ of all $M$. americana populations and the 2 putative hybrid individuals have an $\mathrm{F}_{\mathrm{IS}}$ of essentially $0 . \mathrm{F}_{\mathrm{ST}}$ was 0.438 between pooled M. americana and pooled $M$. caurina . Contrasting pooled M. americana against pooled (insular and mainland) populations of $M$. caurina found similar, high $\mathrm{F}_{\mathrm{ST}}$ estimates $($ mean $=0.44-0.45$, weighted mean $=0.68-0.70)$ with only moderate $\mathrm{F}_{\mathrm{ST}}$ estimates between insular and continental populations of $M$. caurina (mean $=0.01$, weighted mean $=0.11$; Supplemental Information5).F2-statistics (Supplemental Information 6) and $\mathrm{F}_{\mathrm{S}}$ (local inbreeding or relatedness2, Supplemental Information 7) demonstrate similar patterns of genetic differentiation between individuals and species, highlighting divergence within M. caurina . Nucleotide diversity $(\pi)$ was similar across species, but analysis of insular and mainland M. caurina populations separately produced elevated $\pi$ estimates, with the highest values for insular M. caurina (Supplemental Information 8). Insular M. caurina also exhibited the highest positive $D$ value, with mainland $M$. caurina exhibiting only negative and the lowest median $D$ value (Supplemental Information 8).

\section{Tests for introgression}

The most supported ADMIXTURE result parsed six populations $(\mathrm{K}=6$; Fig. 3a): two within each marten species and two putative hybrids, identified as independent populations (KUI, MTX). Although K6 exhibited the greatest $\Delta \mathrm{cv}$ (Supplemental Information 9), we also examined alternative values of K (Lawson et al. 2018; Supplemental Information 10) to thoroughly characterize genetic structure in North AmericanMartes (Janes et al. 2017). The K2 model splits $M$. caurinafrom M. americana, while K3 through K5 models identify additional intraspecific structure. Insular and continental $M$. caurinapopulations were separated under K4 and K6 models, while K7 distinguished each $M$. caurina sample as an independent population (Supplementary Information 10-11). Under all values of K, only two individuals were identified as admixed: KUI and MTX. NegativeF3 -statistics (Table 2) also consistently identified these samples as hybrids between $M$. americana and M. caurina, while all other F3 results were positive or insignificant (Supplemental Information 12-13). Consistent with geography and a K3 ADMIXTURE model, F3 -statistics, among populations identified by K6, found the KUI hybrid to be the result of mixture between the insular populations of each species, while the continental hybrid appears to be a combination of the continental populations of each species (Table 2). Under K2 through K4 models, hybrid samples contain near $50 \%$ genetic proportions corresponding to each species, suggesting that these individuals may represent F1 hybrids or early generational backcrosses (Supplemental Information 11). Consistent with these results, hybrid-class simulations most support the KUI hybrid (empirical admixture proportions: $55 \%$ M. americana , 45\% M. caurina) as an F1 or 48-54\% assignment to each species. Empirical admixture proportions for the MTX hybrid (60\% M. americana, 40\% $M$. caurina ) fall intermediate to simulated admixture proportions for an F1 hybrid and a single generation backcrossed with $M$. americana (73-76\% assignment to the backcrossed species, $22-26 \%$ assignment to the other parental species). Results were identical for simulations on all M. americana and M. caurina and for insular and continental populations of each species, when run separately, indicating that both hybrids represent early generational stage crosses, with MTX potentially the result of a complex backcrossing history between both species. R simulations based on Lavretsky et al. (2016) demonstrate the loss of a signature of 
introgression after four generations of backcrossing into either species (Supplemental Information 14).

Consistent with those backcross estimates, Treemix phylogeny estimations rooted on M. zibellina placed both hybrids as separate sister lineages to the M. americana clade and identified the first most likely gene flow event between MTX and an M. caurina ancestor, followed by a migration event between KUI and $M$. caurina(Supplemental Information 15). Interestingly, the third most likely migration event was estimated between the outgroup M. zibellinaand the KUI hybrid.

F4 statistics show the directionality and intensity of backcrossing is similar across the two hybrids (Supplemental Information 16-17). KUI shares more genetic overlap with insular $M$. caurinacompared to the continental clade and MTX has similar proportions of insular and continental M. caurina alleles (Supplemental Information 16-17). For tests across all individuals, AdmixtureGraph identified KUI as a mix between $\mathrm{CHI}$ and POW (minimal error $=0$ ) and MTX as a cross between ADM and the ancestor of continental $M$. americana (Supplemental Information 18-20). Interestingly, when considering only the populations identified by ADMIXTURE (e.g., pooled continental and insular populations of each species), AdmixtureGraph identified both hybrids as a mix between the continental populations of each species. However, notably there were multiple clustered minimal-error estimates (Supplemental Information 20) that we anticipate will be resolved with increased sample sizes. MixMapper found that the timing of admixture did not differ from the present (0) for either hybrid (Supplemental Information 21).

\section{Demographic histories}

PSMC identified three major demographic histories: distinct insular and continental histories within $M$. caurina and a single general demographic history within $M$. americana with greater variance relative to either M. caurina distribution (Fig. 3b). All M. caurina distributions are lower $\left(\mathrm{N}_{\mathrm{e}}\right)$ than $M$. americana, with insular M. caurina exhibiting the lowest $\mathrm{N}_{\mathrm{e}}$ of all groups examined. Of the populations examined, CHI has the highest historic peak in $\mathrm{N}_{\mathrm{e}}$, while MAK had a larger effective population size recently.

\section{DISCUSSION}

Ice-cover during the last glacial maximum (LGM; 26.5-19 kya) displaced most high-latitude species, forcing them into ice-free glacial refugia (Hultén 1937; Hewitt 2000, 2003; Bennett \& Provan 2008; Clark et al. 2009). The largest documented LGM macro-refugium in North America was located south of the Laurentide and Cordilleran ice sheets in the contiguous U.S., evidenced by fossil data, climatic modeling, and phylogeographic signatures (Graham et al. 1996; Jackson et al. 2000; Holliday et al. 2002), although the extent and complexity of this refugium requires further resolution. Additional LGM refugia are hypothesized in Beringia, the area of exposed continental shelf connecting Alaska to eastern Siberia (Hultén 1937; Abbott \& Brochmann 2003; Hope et al. 2013), and multiple smaller micro-refugia are proposed among the archipelagos of the North Pacific Coast (Heaton et al. 1996; Hewitt 2000; Carrara et al. 2003, 2007; Lacourse et al. 2003; Mathewes \& Clague 2017), although the duration and possible cyclic recurrence of these refugia remains uncertain. Coastal refugia within the Alexander and Haida Gwaii archipelagos could explain high levels of endemism in this region (Cook \& MacDonald 2001; Dawson et al. 2007) and clustered phylogenetic breaks separating insular and continental populations (Colella et al. 2018c; Sawyer et al. 2019) hypothesized to result from post-glacial refugial population expansion limited by secondary contact with closely-related, previously-allopatric taxa (Hewitt 2000). Paleoendemic refugial persistence also explains the rapid reestablishment of complex biotic communities so quickly following deglaciation (Lesnek et al. 2018; Ager 2019).

Significant geographic structure within Pacific martens is consistent with the Coastal Refugium Hypothesis (CRH) (Fig. 3, 4), suggesting the persistence of at least one insular M. caurina population in a North Pacific coastal refugium potentially located along the western fringe of the Alexander or Haida Gwaii archipelagos. The two clades within M. caurina are genetically distinct, parsing an insular and continental lineage, despite mitochondrial nesting (Fig. 2d; Supplemental Information 5). The two insular and continental M. caurina clades are geographically discontinuous (Fig. 1) and estimated to have diverged almost 1 million years ago (Fig. 3b), although PSMC date estimates are highly sensitive to scaling (mutation rate and generation time). Divergence predating the most recent interglacial suggests that insular $M$. caurina may have diverged 
from continental populations over multiple glacial cycles, perhaps initially in a coastal refugium and then subsequently on one or more NPC islands. Our genomic results initially contradict the fossil record, which shows a scarcity of fossils on POW Island during the LGM ( $20-15$ kya, Lesnek et al. 2018) and documents martens appearing on POW during the late Pleistocene (>14 kya) and early Holocene (9-14 kya, Heaton \& Grady 2003; Pauli et al. 2015). Absence of martens and other mammals in the Southeast Alaskan fossil record during the LGM may reflect sampling bias, as most dated fossil materials from the region were collected from the Shuká Káa cave at the northern end of POW. Insular M. caurina have not been documented on POW and this site was likely ice-covered at the peak of the LGM (Lesnek et al. 2018). Even so, a number of meso-carnivore teeth from Shuká Káa cave morphologically identified as mink (Mustela vison ) may instead mark the early presence of insular M. caurina (Heaton \& Grady 2003), as these species have similar tooth morphology. Similar to misidentifications of Pleistocene coastal black bear (Ursus americanus ) fossils from POW that were originally listed as brown bears (Ursus arctos ) due to size differences over evolutionary timescales (Lindqvist pers. obs.), insular M. caurina are physically larger than bothM. americana and continental M. caurina (Colella et al. 2018b) which may confound taxonomic assignment of dentition. The persistence of diverse communities of large terrestrial mammals, including caribou, bears, and foxes, evident in the fossil record both pre- and post-LGM (Lesnek et al. 2018), points to a higher potential for local refugial persistence through the LGM over the recolonization of these outer islands from mainland sources since the Holocene (Ager 2019).

The viability of a coastal migration route for human colonization of the Americas hinges on our understanding of glacial extent and biotic community composition along the NPC during the late Pleistocene. Geological investigations of southeast Alaska have produced mixed results. Bathymetry (Carrara et al. 2003, 2007) and palynology (Ager 2019) support the persistence of coastal refugia, while cosmogenic exposure dating has shed doubt on hypothesized refugial locations (Lesnek et al. 2018). Multiple signatures of refugial persistence across taxa (Foster 1965; Heaton et al. 1996; Hewitt 2000, 2003; Weckworth et al. 2005; Colella et al. 2018c; Sawyer et al. 2019) is detailing increasingly complex refugial communities along the coast.

For marten, the laterally dilated cranial shape of insular M. caurina hints at a dietary shift towards the consumption of marine prey items (Colella et al. 2018b), also documented in stomach contents (Giannico \& Nagorsen 1989) and also reflected in insular wolves of the NPC (Darimont et al. 2009; Muñoz-Fuentes et al. 2010). Martens rely on deep persistent snow and complex forest structure (Proulx 1997; Pauli et al. 2013; Manlick et al. 2017; Martin et al. 2019) for predator avoidance, thermal management, and efficient locomotion, suggesting that refugial ecosystems would have contained forest community assemblages. Access to both marine and terrestrial prey items and timber resources along a NPC migration route, would have enhanced human survivorship during an early pulse of human migration into the Americas via the Pacific coast (Fladmark 1979; Dixon 1993).

The insular-continental biogeographic and phylogenetic break within $M$. caurina is largely consistent with signatures from numerous other NPC paleoendemics (bears, Heaton et al. 1996; deer, Latchet al. 2009; ermine, Colella et al. 2018c; shrews, Demboski \& Cook 2001; deer mice, Sawyer et al. 2019) and also evident in the few associated parasites examined to date (Soboliphyme baturini, Koehler et al. 2007, 2009; Hoberget al. 2012). Disparate distributions of insular lineages across these heterogeneous archipelagos suggests that the geographic pattern and duration of refugial isolation may vary across climate cycles, depending on the ecological plasticity and dispersal abilities of incumbent species. Insular 'ABC' brown bears (Ursus arctos, Heaton et al. 1996), for example, are currently geographically restricted to the three northern most islands of the Alexander Archipelago (Admiralty, Baranof, Chichagof), while the insular black bear lineage (Byun et al. 1997) has a more southerly distribution encompassing southern Alexander Archipelago islands, the Haida Gwaii Archipelago, Vancouver Island, and coastal British Columbia. Under the assumption of niche conservatism, this phylogeographic pattern suggests a cooler, northern refugium within the Alexander Archipelago and a slightly warmer, perhaps more heavily vegetated refugial ecosystem to the south, either in the southern Alexander Archipelago or Haida Gwaii. Early paleoclimatic models for NPC refugia hypothesized these areas to be primarily tundra and unable to support forest-associated taxa such as black bears and martens (Hansen \& Engstrom 1996; Ager 2007). More recently however, palynological investigations 
and radiocarbon dating of postglacial peat and sediment cores indicate that coastal forests similar to today's forests existed in the Alexander Archipelago during the last interglacial (Ager 2019). Rapid colonization of the western-most islands by pine trees (Picea) immediately following glacial recession ( $\sim 17 \mathrm{kya})$ hints at the potential refugial persistence of coniferous forests (Lesnek et al. 2018; Ager 2019) and parallels our hypothesis that refugial persistence of insular $M$. caurina is more likely than post-glacial recolonization.

Comparative demography also identified at least three major evolutionary trajectories: M. americana, continental M. caurina (Fig. 3b) and insular M. caurina, consistent with the CRH. Martes americana distributions of effective population size are overall higher than those of $M$. caurina clades, consistent with the contiguous contemporary range of this species and historical divergence in and subsequent expansion from a single, large eastern refugium (Stoneet al. 2002). Within M. americana, Chichagof Island exhibits the highest effective population size $\left(\mathrm{N}_{\mathrm{e}}\right)$, followed by central Alaska (Fig. 3b). Although high $\mathrm{N}_{\mathrm{e}}$ is surprising for an insular population, Chichagof Island received iterative translocations of M. americana in the mid-1900s from multiple source populations, including four other islands in southeast Alaska (Baranof, Wrangell, Mitkof [Petersburg], and Revillagigedo [Ketchikan] islands) and one distant continental locality (Polly Creek, in central AK). These introductions may inflate population size estimates as a consequence of outbreeding (Paul 2009) and make the historical distribution of $\mathrm{N}_{\mathrm{e}}$ for this individual resemble that of its source populations (e.g., MAK). In contrast, Prince of Wales Island (POW) received introductions from only two proximate sources: Revillagigedo and Mitkof islands (Burris \& McKnight 1973). Revillagigedo Island shows a similar demographic history to POW, suggesting those translocations resulted in successful establishment (Elkins \& Nelson 1954). Although our results hint at insular-continental structure within M. americana (Fig. 3), this signal is muddled by historical wildlife translocations and remains unresolved from a nuclear perspective (Fig. 2). Relative to M. americana, both continental and insular M. caurina have persistently smaller effective population sizes.

Among continental species, a common response to rising temperatures is the upward distributional shift in elevation (or latitude) to retain suitable environmental conditions (Hampe \& Jump 2011). The fragmented contemporary distribution of continental M. caurina populations (U.S. west coast, Pacific Northwest forests, mountaintops of the American Southwest; Fig. 1) is consistent with the retention of a cooler paleoclimatic niche for species experiencing increasing fragmentation under current warming conditions (Brown 1971; Anderson et al.2000; Parmesan 2006; Hampe \& Jump 2011; Meng et al. 2019). Relative to all continental taxa, insular $M$. caurina show a significantly depressed effective population size through time, with the highest overall inbreeding coefficients. Although likely a consequence of island life, small effective population sizes and high levels of inbreeding place insular martens at an elevated risk of extinction (Frankham 1998; Rybicki \& Hanski 2013).

Refugial divergence along the NPC also explains the disjunct contemporary distribution of M. caurina (Fig. 1). Along the NPC, M. caurina inhabits at least three islands; however, Admiralty Island in Southeast Alaska is more than $300 \mathrm{~km}$ north of the two insular Canadian populations. Although geographic disjunction across three islands is substantial, the genetic similarly of these island populations points to historical divergence in a single coastal refugium and a potentially more widespread historical distribution of insular $M$. caurina throughout NPC islands. Higher density sampling across the NPC will be necessary to refine the geographic limits of insular and continental $M$. caurina clades. Refugial divergence of insular M. caurina is further supported by the persistence of the insular lineage in the Kuiu Island hybrid zone (Dawson et al. 2017), ${ }^{20 \mathrm{~km}}$ south of Admiralty Island, relictual signatures of M. caurina on POW (Pauli et al. 2015), and associated nematodes (Soboliphyme baturini) on Chichagof Island (Koehleret al. 2007, 2009; Hoberg et al. 2012). Chichagof martens harbor distinctive nematodes that are phylogenetically close to S. baturini found in other populations of $M$. caurina, suggesting $M$. caurina or a 'ghost' marten lineage may persist or have persisted on this island until relatively recently (Koehler et al. 2007, 2009; Hoberg et al. 2012). Similarly, POW is hypothesized to have been colonized by multiple natural sources (Pauliet al. 2015) and iterative translocations of $M$. americanato this island were surprisingly successful considering as few as 10 martens (4 females) were introduced to the island (Paul 2009). In contrast, our genomic analyses did not find M. caurina alleles in either of the individuals sequenced from islands that received translocations of M. americana. Instead, we 
found each island to be genetically aligned with $M$. americana and their translocation source populations: Chichagof Island with central Alaska and POW with Revillagigedo Island (Fig. 2 and 3). Overall our results suggest that $M$. caurina were either not present on these islands prior to translocations or were recently replaced or swamped by introduced or invading M. americana. Interspecific competition, outbreeding, or the introduction of foreign pathogens among other variables may have impacted native $M$. caurina (Plein et al. 2016; Colellaet al. 2018b; Northover et al. 2018). Ultimately, until additional hybrids are sequenced, our results discourage the translocation of American marten for the genetic rescue or restoration of coastal martens due to potential swamping and emphasize the importance of careful source population selection, as the NPC harbors significant cryptic diversity and complex evolutionary histories.

We detected a hybrid individual collected from each natural mixing zone: Kuiu Island Alaska and western Montana in the northern Rocky Mountains (Table 2; Fig. 2-4; Supplemental Information 9-16). Both hybrids were female, had M. americana mitochondrial haplotypes (Fig. 2d), and mixed nuclear ancestry, with the Montana hybrid containing continental $M$. caurina alleles and the Kuiu hybrid containing insular M. caurina alleles (Table 2; Supplemental Information 10-13, 16-17). Both admixed individuals were identified as early generational-stage hybrids (e.g., F1's or a single generation backcrossed with M. americana, Supplemental Information 11-12) with introgression occurring recently (Supplemental Information 21). Although sample sizes are small, the absence of late-generational hybrids is surprising, especially for the Montana zone which has persisted for many generations (Wright 1953). Detection of only early-generational hybrids is consistent with the presence of hybrid incompatibilities, where F1 hybrids experience a temporary elevation in fitness (heterosis) compared to later generational-stage hybrids (e.g., F2 and beyond) that may suffer outbreeding depression as a result of disrupted co-adapted gene complexes (Todesco et al. 2016). The disruption of coadapted gene complexes or genes involved in local adaptation via introgression, and particularly loci involved in disease and pathogen resistance (Alibert et al. 1994), may pose a particular challenge to naïve insular taxa. This hypothesis warrants further genomic investigation with fine-scale sampling from within hybrid zones and translocated islands.

Differentiation between insular and continental M. caurina was suggested previously based on reducedrepresentation genetic approaches (Demboski et al. 1999, 2001; Stone et al. 2002; Smallet al. 2003; Dawson et al. 2017), but the extent of divergence was unknown. A genomic pattern of refugial divergence may be more widespread than previously suspected and additional forest-associated taxa, that are not well represented in the fossil record, may have persisted in NPC refugia. Our results underscore the importance of reevaluating work previously based on one or a few genes, as genomic resolution continues to provide unexpected insight into the evolutionary complexities of coastal refugia (Miller et al. 2012; Colella et al. 2018c) and complex landscapes and holds great promise to unravel complexity across time.

\section{ACKNOWLEDGEMENTS}

We thank the Center for Advanced Research Computing (UNM), the Center for Computational Research (UB), and T. L. Burkhard for computational support; the Museum of Southwestern Biology and the Burke Museum for providing samples; R. W. Flynn, C. T. Seaton, K. Marsh, N. Anderson, A. Merrill, N. E. Dokuchaev, B. Castle, B. Dearden, E. Youngberg Jr., R.L. Pharr, L. Dickerson for facilitating specimen acquisition; S. Liphardt and K. Derieg for thoughtful independent reviews. Research reported in this publication was supported by the Shadle Fellowship (American Society of Mammalogists), USGS Cooperative Agreement, NSF 1258010, and the National Institute of General Medical Sciences of the National Institutes of Health under award number P30GM110907. The content is solely the responsibility of the authors and

does not necessarily represent the official views of the National Institutes of Health. Use of trade, firm, or product names is for descriptive purposes only and does not imply endorsement by the U.S. Government.

\section{REFERENCES}

Ager, T. (2007). Vegetation development on Heceta Island, southeastern Alaska during the Late Glacial and Holocene. Geological Society of America Abst. Prog. , 39 , 17.

Ager, T. A. (2019). Late Quaternary vegetation development following deglaciation of northwestern Alexan- 
der Archipelago, Alaska.Frontiers in Earth Science, 7 (104), 1-25.

Abbott, R. J., Barton, N. H., \& Good, J. M. (2016). Genomics of hybridization and its evolutionary consequences. Molecular Ecology , 25 (11), 2325-2332.

Abbott, R., \& Brochmann, C. (2003). History and evolution of the Arctic flora: in the footsteps of Eric Hultén. Molecular Ecology ,12 , 299-313.

Alexander, D. H., Novembre, J., \& Lange, K. (2009). Fast model-based estimation of ancestry in unrelated individuals. Genome Research ,19 , 1655-1664.

Alibert, P., Penaud, S., Dod, B., Bonhomme, F., \& Auffray, J.-C. (1994). Fluctuating asymmetry in the Mus musculus hybrid zone: a heterotic effect in disrupted co-adapted genomes. Proceedings of the Royal Society B: Biological Sciences , $258,53-59$.

Anderson, R., Betancourt, J., Mead, J., Hevly, R., \& Adam, D. (2000). Middle- and late-Wisconsin paleobotanic and paleoclimatic records from the southern Colorado Plateau, USA. Palaeogeography, Palaeoclimatology, Palaeoecology , 155, 31-57.

Andrews, S. (2010). FastQC: a quality control tool for high throughput sequence data. Available online at: http://www.bioinformatics.babraham.ac.uk/projects/fastqc .

Arnold, M. (1997). Natural hybridization and evolution . Oxford, UK: Oxford University Press.

Bennett, K. D., \& Provan, J. (2008). What do we mean by "refugia"?Quaternary Science Reviews , 27 , 2449-2455.

Bolger, A. M., Lohse, M., \& Usadel, B. (2014). Trimmomatic: A flexible trimmer for Illumina sequence data. Bioinformatics ,30 (15), 2114-2120.

Brown, J. (1971). Mammals on mountaintops: nonequilibrium insular biogeography. The American Naturalist , 105 (945), 467-478.

Burris, O. E., \& McKnight, D. E. (1973). Game Transplants in Alaska (pp. 1-57) [Wildlife Technical Bulletin Alaska Department of Fish and Game]. Alaska Department of Fish and Game.

Buskirk, S. W., Bowman, J., \& Gilbert, J. (2012). Population biology and matrix demographic modeling of American martens and fishers. InBiology and Conservation of Martens, Sables, and Fishers: A New Synthesis (K.B. Aubry, W.J. Zielinski, M.G. Raphael, G. Proulx, S.W. Buskirk eds., pp. 77-92). Ithaca, NY: Cornell University Press.

Byun, S. A., Koop, B. F., \& Reimchen, T. E. (1997). North American black bear mtDNA phylogeography: Implications for morphology and the Haida Gwaii glacial refugium controversy. Evolution ,51 (5), 1647-1653.

Carlson, R. J., \& Baichtal, J. F. (2015). A predictive model for locating early Holocene archaeological sites based on raised shell-bearing strata in Southeast Alaska. Geoarchaeology ,30 , 120-138.

Carrara, P., Ager, T. A., \& Baichtal, J. F. (2007). Possible refugia in the Alexander Archipelago of southeastern Alaska during the late Wisconsin glaciation. Canadian Journal of Earth Sciences ,44, 229-244.

Carrara, P., Ager, T. A., Baichtal, J. F., \& VanSistine, D. P. (2003). Map of glacial limits and possible refugia in the southern Alexander Archipelago, Alaska during the Late Wisconsin Glaciation. U.S. Geological Survey, Miscellaneous Field Studies Map MP-2424, 1-13.

Clark, P., Dyke, A., Shakun, J., Carlson, A., Clark, J., Wohlfarth, B., .. McCabe, A. (2009). The Last Glacial Maximum. Science ,325, 710-714.

Colella, J. P., Johnson, E. J., \& Cook, J. A. (2018b). Reconciling molecules and morphology in North American Martes. Journal of Mammalogy, 99 (6), 1323-1335. 
Colella, J. P., Lan, T. Y., Schuster, S. C., Talbot, S. L., Cook, J. A., \& Lindqvist, C. (2018c). Whole-genome analysis of Mustela erminea finds that pulsed hybridization impacts evolution at high-latitudes. Nature Communications Biology, 1 (1), 51.

Colella, J., Wilson, R., Talbot, S., \& Cook, J. (2018a). Implications of introgression for wildlife translocations: the case of North American martens. Conservation Biology , 1572-9737. doi: https://doi.org/10.1007/s10592018-1120-5

Cook, J. A., \& MacDonald, S. O. (2001). Should endemism be a focus of conservation efforts along the North Pacific Coast of North America?Biological Conservation, 97 , 207-213.

Danecek, P., Auton, A., Abecasis, G., Albers, C. A., Banks, E., DePristo, M. A., ... 1000 Genome Project Data Process Subgroup. (2011). The variant call format and VCFtools. Bioinformatics ,27 (15), 2156-2158.

Darimont, C., Paquet, P., \& Reimchen, T. (2009). Landscape heterogeneity and marine subsidy generate extensive intrapopulation niche diversity in a large terrestrial vertebrate. Journal of Animal Ecology , 78 , $126-133$.

Davis, L., Madsen, D., Becerra-Valdivia, L., Higham, T., Sisson, D., Skinner, S., .. Cheyney, M. (2019). Davis, Loren G., et al. "Late Upper Paleolithic occupation at Cooper's Ferry, Idaho, USA, 16,000 years ago. Science, 365 (6456), 891-897.

Dawson, N. G., MacDonald, S. O., \& Cook, J. A. (2007). Endemic Mammals of the Alexander Archipelago. Southeast Alaska Conservation Assessment - Chapter 6.7 , 1-11.

Dawson, N. G., Colella, J. P., Small, M. P., Stone, K. D., Talbot, S. L., \& Cook, J. A. (2017). Historical biogeography sets the foundation for contemporary conservation of martens (genus Martes ) in northwestern North America. Journal of Mammalogy , 98 (3), 715-730.

Devièse, T., Stafford Jr, T., Waters, M., Wathen, C., Comeskey, D., Becerra-Valdivia, L., \& Higham, T. (2018). Increasing accuracy for the radiocarbon dating of sites occupied by the first Americans. Quaternary Science Reviews , $198,171-180$.

Demboski, J. R., \& Cook, J. A. (2001). Phylogeography of the dusky shrew, Sorex monticolus (Insectivora, Soricidae): insight into deep and shallow history in northwestern North America. Molecular Ecology , 10 (5), $1227-1240$.

Demboski, J., Stone, K., \& Cook, J. (1999). Further perspectives on the Haida Gwaii glacial refugium. Evolution, 53 (6), 2008-2012.

Dixon, E. (1993). Quest for the Origins of the First Americans . Albuquerque, NM: University of New Mexico Press.

Dixon, E., Heaton, T., Lee, C., Fifield, T., Coltrain, J., Kemp, B., \& et al. (2014). Evidence of maritime adaptation and coastal migration from Southeast Alaska. In Kennewick Man: The Scientific Investigation of an Ancient American Skeleton (eds. D.W. Owsley and R. L. Jantz). Texas: Texas A\&M University Press.

Durand, E. Y., Patterson, N., Reich, D., \& Slatkin, M. (2011). Testing for ancient admixture between closely related populations. Molecular Biology and Evolution , 28 , 2239-2252.

Durbin, K. (1999). Tongass: Pulp Politics and the Fight for the Alaska Rain Forest . Corvallis, OR: Oregon State University Press.

Elkins, W. A., \& Nelson, U. C. (1954). Wildlife introductions and transplants in Alaska. Proceedings of the 5th Alaska Science Conference, 21.

Erlandson, J. M., Graham, M., Bourque, B., Corbett, D., Estes, J., \& Steneck, R. (2007). The kelp highway hypothesis: marine ecology, the coastal migration theory, and the peopling of the Americas. The Journal of Island and Coastal Archaeology , 2 (2), 161-174. 
Fedorov, V. B., \& Stenseth, N. C. (2002). Multiple glacial refugia in the North American Arctic: inference from phylogeography of the collared lemming (Dicrostonyx groenlandicus ). Proceedings of the Royal Society of London Series B, Biological Sciences , 269 , 2071-2077.

Fenichel, E., Tsao, J., Jones, M., \& Hickling, G. (2008). Fish pathogen screen and its influence on the likelihood of accidental pathogen introduction during fish translocations. Journal of Aquatic Animal Health , 20 (1), 19-28.

Fladmark, K. (1979). Routes: Alternate migration corridors for early man in North America. American Antiquity , 44 , 55-69.

Foster, J. B. (1965). The evolution of the mammals of the Queen Charlotte Islands, British Columbia. B.C. Prov. Mus. Occas. Pap. No. 14, 1-130.

Frankham, R. (1998). Inbreeding and extinction: island populations. Conservation Biology, 12 (3), 665-675.

Genovart, M. (2009). Natural hybridization and conservation.Biodiversity and Conservation, 18 (6), 1435.

Giannico, G. R., \& Nagorsen, D. W. (1989). Geographic and sexual variation in the skull of Pacific coast marten (Martes americana ). Canadian Journal of Zoology , 67, 1386-1393.

Graham, R. W., Lundelius, E. L., Graham, M. A., Schroeder, E. K., Toomey, R. S., Anderson, E., ... Guthrie, R. D. (1996). Spatial responses of mammals to late Quaternary environmental fluctuations.Science , 272 (5268), 1601-1606.

Green, R. E., Krause, J., Briggs, A. W., Maricic, T., Stenzel, U., Kircher, M., ... et al. (2010). A draft sequence of the Neandertal genome. Science , 328 , 710-722.

Hampe, A., \& Jump, A. (2011). Climate relicts: past, present, future.Annual Review of Ecology, Evolution, and Systematics , 42, 313-333.

Hansen, B. C. S., \& Engstrom, D. R. (1996). Vegetation history of Pleasant Island, southeastern Alaska, since 13,000 yr BP.Quaternary Research , 46 , 161-175.

Harrison, R. G., \& Harrison, R. G. (1993). Hybrid zones and the evolutionary process . Oxford, UK: Oxford University Press.

Heaton, T. D., \& Grady, F. (2003). The Late Wisconsin Vertebrate History of Prince of Wales Island, Southeast Alaska. In Ice Age Cave Faunas of North America (Schubert, B.W., Mead, J.I., Graham, R.W., pp. 17-53). Bloomington, IN: Indiana University Press.

Heaton, T. H., Talbot, S. L., \& Shields, G. F. (1996). An ice age refugium for large mammals in the Alexander Archipelago, southeastern Alaska. Quaternary Research , 46 (2), 186-192.

Heusser, C. J. (1989). North Pacific coastal refugia - the Queen Charlotte Islands in perspective. In The Outer Shores (G.G.E. Scudder and N. Gessler eds., p. 327). University of British Columbia.

Hewitt, G. (2000). The genetic legacy of Quaternary ice ages.Nature , 405 , 907-913.

Hewitt, G. (2003). Ice Ages: their impact on species distributions and evolution. In Evolution of Planet Earth (Rothschild, L. J. and Lister, A. M. (eds), pp. 339-361). Academic Press.

Hoberg, E. P., Koehler, A. V. A., \& Cook, J. A. (2012). Complex host-parasite systems in Martes implications for conservation biology of endemic faunas. In Biology and Conservation of Martens, Sables, and Fishers: A New Synthesis (Aubry, K. B., Zielinski, W. J., Raphael, M. G., Proulx, G. Buskirk, S. W., pp. 39-57). Ithaca, NY: Cornell University Press.

Holliday, V., Knox, J., Running, G., Mandel, R., \& Ferring, C. (2002). The physical geography of North America (ed. Orme, AR). Oxford, UK: Oxford University Press. 
Hope, A., Takebayashi, N., Galbreath, K., Talbot, S., \& Cook, J. (2013). Temporal, spatial and ecological dynamics of speciation among amphi-Beringian small mammals. Journal of Biogeography ,40 , 415-429.

Hultén, E. (1972). Outline of the history of arctic and boreal biota during the Quaternary period: their evolution during and after the glacial period as indicated by the equiformal progressive areas of present plant species . University of California: J. Cramer.

Jackson, S., Webb, R., Anderson, K., Overpeck, J., Webb III, T., Williams JW, \& Hansen, B. (2000). Vegetation and environment in eastern North America during the last glacial maximum. Quaternary Science Reviews , 19 (6), 498-508.

Janes, J. K., Miller, J. M., Dupuis, J. R., Malenfant, R. M., Gorrell, J. C., Cullingham, C. I., \& Andrew, R. L. (2017). The K = 2 conundrum. Molecular Ecology 26 (14), 3594-3602.

Koehler, A. V., Hoberg, E. P., Dokuchaev, N. E., \& Cook, J. A. (2007). Geographic and host range of the nematode Soboliphyme baturiniacross Beringia. Journal of Parasitology , 93 (5), 1070-1083.

Koehler, A. V., Hoberg, E. P., Dokuchaev, N. E., Tranbenkova, N. A., Whitman, J. S., Nagorsen, D. W., \& Cook, J. A. (2009). Phylogeography of a Holarctic nematode, Soboliphyme baturini, among mustelids: climate change, episodic colonization, and diversification in a complex host-parasite system. Biological Journal of the Linnean Society ,96 (3), 651-663.

Kulathinal, R. J., Stevison, L. S., \& Noor, M. A. (2009). The genomics of speciation in drosophila: diversity, divergence, and introgression estimated using low-coverage genome sequencing. PLoS Genetics ,5 (7), e1000550.

Kumar, S., \& Subramanian, S. (2002). Mutation rates in mammalian genomes. Proceedings of the National Academy of Sciences ,99 (2), 803-808.

Lacourse, T., Mathewes, R., \& Fedje, D. (2003). Paleoecology of late-glacial terrestrial deposits within situ conifers from the submerged continental shelf of western Canada. Quaternary Research , 60 (2), 180-188.

Latch, E., Heffelfinger, J., Fike, J., \& Rhodes, O. (2009). Species-wide phylogeography of North American mule deer (Odocoileus hemionus ): cryptic glacial refugia and postglacial recolonization. Molecular Ecology , 2009 (18), 1730-1745.

Lavretsky, P., Peters, J., Winker, K., Bahn, V., Kulikova, I., Zhuravlev, Y., .. McCracken, K. (2016). Becoming pure: identifying generational classes of admixed individuals within lesser and greater scaup populations. Molecular Ecology , 25 (3), 661-674.

Lawson, D., Van Dorp, L., \& Falush, D. (2019). A tutorial on how not to over-interpret STRUCTURE and ADMIXTURE bar plots. Nature Communications , 9 (1), 3258.

Leaché, A. D., Banbury, B. L., Felsenstein, J., \& Stamatakis, A. (2015). Short tree, long tree, right tree, wrong tree: New acquisition bias corrections for inferring SNP phylogenies. Systematic Biology , 64 (6).

Lesnek, A., Briner, J., Linqvist, C., Baichtal, J., \& Heaton, T. (2018). Deglaciation of the Pacific coastal corridor directly preceded the human colonization of the Americas. Science Advances, eaar5040.

Li, H., \& Durbin, R. (2010). Fast and accurate long-read alignment with Burrows-Wheeler transform. Bioinformatics , 26 , 589-595.

Li, H., Handsaker, B., Wysoker, A., Fennel, T., Ruan, J., Homer, N., .. 1000 Genome Project Data Process Subgroup. (2009). The sequence alignment/map format and SAMtools. Bioinformatics , 25 (16), 2078-2079.

Li, H., \& Durbin, R. (2011). Inference of human population history from whole genome sequence of a single individual. Nature ,475 (7357), 493-496. 
Lipson, M., Loh, P.-R., Levin, A., Reich, D., Patterson, N., \& Berger, B. (2013). Efficient moment-based inference of admixture parameters and sources of gene-flow. Molecular Biology and Evolution ,30 (8), 17881802.

Mackie, Q., Fedje, D., \& McLaren, D. (2018). Archaeology and sea level change on the British Columbia coast. Canadian Journal of Archaeology , 42, 74-91.

Mailund, T., Leppälä , K., \& Nielsen, S. (2016). AdmixtureGraph: Admixture Graph Manipulation and Fitting (Version R 1.0.1). Retrieved from https://github.com/mailund/admixture_graph

Manlick, P. J., Woodford, J. E., Gilbert, J. H., Eklund, D., \& Pauli, J. N. (2017). Augmentation provides nominal genetic and demographic rescue for an endangered carnivore. Conservation Letters ,10 (2), 178-185.

Margold, M., Gosse, J., Hidy, A., Woywitka, R., Young, J., \& Froese, D. (2019). Beryllium-10 dating of the Foothills Erratics Train in Alberta, Canada, indicates detachment of the Laurentide Ice Sheet from the Rocky Mountains at 15 ka. Quaternary Research , 1-14. doi: 10.1017/ qua.2019.10

Martin, M., Moriarty, K., \& Pauli, J. (2019). Forest structure and snow depth alter the movement patterns and subsequent expenditures of a forest carnivore, the Pacific marten. Oikos .

Martin, S. H., Davey, J. W., \& Jiggins, C. D. (2015). Evaluating the Use of ABBA-BABA Statistics to Locate Introgressed Loci. Molecular Biology and Evolution , 32 (1), 244-257. doi: 10.1093/molbev/msu269

Massei, G., Quy, R., Gurney, J., \& Cowan, D. (2010). Can translocations be used to mitigate human-wildlife conflicts? Wildlife Research ,37 (5), 428-439.

Mathewes, R. W., \& Clague, J. J. (2017). Paleoecology and ice limits of the early Fraser glaciation (Marine Isotope Stage 2) on Haida Gwaii, British Columbia, Canada. Quaternary Research , 88 (2), 277-292.

McKenna, A., Hanna, M., Banks, E., Sivachenko, A., Cibulskis, K., Kernytsky, A., . . DePristo, M. A. (2010). The Genome Analysis Toolkit: a MapReduce framework for analyzing next-generation DNA sequencing data. Genomic Research, 20 (9), 1297-1303.

McLaren, D., Fedje, D., Dyck, A., Mackie, Q., Gauvreau, A., \& Cohen, J. (2018). Terminal Pleistocene Epoch human footprints from the Pacific coast of Canada. PLoS One , 13 , e0193522.

McNeely, J. (2001). A global strategy on Invasive alien species.Cambridge, UK: IUCN Gland, Switzerland, and Cambridge, U.K., in collaboration with the Global Species Programme. IUCN Publication Services Unit.

Meng, H.-H., Zhou, S.-S., Jiang, X.-L., Gugger, P., Tan, Y.-H., \& Li, J. (2019). Are mountaintops climate refugia for plants under global warming? A lesson from high-mountain oaks in tropical rainforest.Alpine Botany , 129 (2), 175-183.

Merriam, C. H. (1890). Description of twenty-six new species of North American mammals. North American Fauna , 4 , 1-55.

Muñoz-Fuentes, V., Darimont, C., Paquet, P., \& Leonard, J. (2010). The genetic legacy of extirpation and re-colonization in Vancouver Island wolves. Conservation Genetics , 11 (2), 547-556.

Nadachowska-Brzyska, K., Burri, R., Smeds, L., \& Ellegren, H. (2016). PSMC analysis of effective population sizes in molecular ecology and its application to black-and-white Ficedula flycatchers.Molecular Ecology , 25 (5), 1058-1072.

Northover, A., Lymbery, A., Wayne, A., Godfrey, S., \& Thompson, R. (2018). The hidden consequences of altering host-parasite relationships during fauna translocations. Biological Conservation, 220 , 140-148.

Parmesan, C. (2006). Ecological and Evolutionary Responses to Recent Climate Change. Annual Review of Ecology, Evolution, and Systematics , 37 (1), 637-669. doi: 10.1146/annurev.ecolsys.37.091305.110100 
Patterson, N., Moorjani, P., Luo, Y., Mallick, S., Rohland, N., Zhan, Y., .. Reich, D. (2012). Ancient Admixture in Human History. Genetics , 192 (3), 1065-1093. doi: 10.1534/genetics.112.145037

Paul, T. (2009). Game transplants in Alaska. (Technical Bulletin No. No. 4; p. 150). Juneau, Alaska: Alaska Department of Fish and Game, Division of Wildlife Conservation.

Pauli, J., Moss, W., Manlick, P., Fountain, E., Kirby, R., Sultaire, S., .. Heaton, T. (2015). Examining the uncertain origin and management role of martens on Prince of Wales Island, Alaska. Conservation Biology, 29 (5), 1257-1267.

Pauli, J., Smith, W., \& Ben-David, M. (2012). Quantifying dispersal rates and distances in North American martens: a test of enriched isotope labeling. Journal of Mammalogy , 93 (2), 390-398.

Pauli, J., Zuckerberg, B., Whiteman, J., \& Porter, W. (2013). The subnivium: a deteriorating seasonal refugium. Frontiers in Ecology and the Environment , 11 (5), 260-267.

Peng, X., Alföldi, J., Gori, K., Eisfeld, A. J., Tyler, S. R., Tisoncik-Go, J., ... Katze, M. G. (2014). The draft genome sequence of the ferret (Mustela putorius furo ) facilitates study of human respiratory disease. Nature Biotechnology , 32 (12), 1250-1255. doi: 10.1038/nbt.3079

Peter, B. M. (2016). Admixture, population structure andF -statistics. Genetics , 202 (4), 1485-1501. doi: https://doi.org/10.1534/genetics.115.183913

Pickrell, J. K., \& Pritchard, J. K. (2012). Inference of population splits and mixtures from genome-wide allele frequency data. PLoS Genetics , 8 (11), e1992967. doi: 10.1371/journal.pgen.1002967

Plein, M., Bode, M., Moir, M., \& Vesk, P. (2016). Translocation strategies for multiple species depend on interspecific interaction type. Ecological Applications , 26 (4), 1186-1197.

Powell, R. A., Lewis, J.C., J. C., Slough, B. G., Brainerd, S. M., Jordan, N. R., Abramov, A. V., ... Murakami, T. (2012). Evaluating translocations of martens, sables, and fishers: testing model predictions with field data. In Biology and Conservation of Martens, Sables, and Fishers: A New Synthesis (Aubry, K.B., Zielinski, W.J., Raphael, M.G., Proulx, G., Buskirk S.W., p. 536). Ithaca, NY: Cornell University Press.

Prenter, J., MacNeil, C., Dick, J. T., \& Dunn, A. M. (2004). Roles of parasites in animal invasions. Trends in Ecology $\mathscr{G}$ Evolution ,19 (7), 385-390.

Proulx, G. (1997). Martes: Taxonomy, ecology, techniques, and management . Edmonton, AB: Provincial Museum of Alberta.

Puckett, E. E., Etter, P. D., Johnson, E. A., \& Eggert, L. S. (2015). Phylogeographic Analyses of American Black Bears (Ursus americanus ) Suggest Four Glacial Refugia and Complex Patterns of Postglacial Admixture. Molecular Biology and Evolution ,32 (9), 2338-2350. doi: 10.1093/molbev/msv114

Purcell, S., Neale, B., Todd-Brown, K., Thomas, L., Ferreira, M. A. R., Bender, D., .. Sham, P. C. (2007). PLINK: a toolset for whole-genome association and population-based linkage analysis.American Journal of Human Genetics , 81 (3), 559-575.

Rybicki, J., \& Hanski, I. (2013). Species-area relationships and extinctions caused by habitat loss and fragmentation. Ecology Letters , 16 (s1), 27-38.

Sawyer, Y. E., MacDonald, S. O., Lessa, E. P., \& Cook, J. A. (2019). Living on the edge: exploring the role of coastal refugia and island biology in the Alexander Archipelago of Alaska. Ecology and Evolution , 9 , 1777-1797.

Scudder, G. G. E. \& Gessler, N. (1989) The Outer Shores . Queen Charlotte Islands Museum. Queen Charlotte City, B. C. Pp. 327. 
Small, M. P., Stone, K. D., \& Cook, J. A. (2003). American marten (Martes americana) in the Pacific Northwest: population differentiation across a landscape fragmented in time and space.Molecular Ecology , $12(1), 89-103$.

Stamatakis, A. (2014). RAxML Version 8: A tool for phylogenetic analysis and post-analysis of large phylogenies. Bioinformatics ,30 (9), 1312-1313.

Stone, K. D., Flynn, R. W., \& Cook, J. A. (2002). Post-glacial colonization of northwestern North America by the forest-associated American marten (Martes americana, Mammalia: Carnivora: Mustelidae). Molecular Ecology , 11 (10), 2049-2063.

Swenson, N. G., \& Howard, D. J. (2005). Clustering of contact zones, hybrid zones, and phylogeographic breaks in North America. The American Naturalist, 166 (5), 581-591.

Thomas, M. A., Roemer, G. W., Donlan, C. J., Dickson, B. G., \& Malaney, J. L. (2013). Gene tweaking for conservation. Nature, $501,485-486$.

Todesco, M., Pascual, M. A., Owens, G. L., Ostevik, K. L., Moyers, B. T., Hübner, S., .. Rieseberg, L. H. (2016). Hybridization and extinction. Evolutionary Applications , 9 (7), 892-908. doi: 10.1111/eva.12367

Turton, W. (1806). A general system of nature, through the three grand kingdoms of animals, vegetables, and minerals. (Vol. 1). London: Lackington and Allen.

Twyford, A. D., \& Ennos, R. A. (2012). Next-generation hybridization and introgression. Heredity , 108 (3), 179-189.

U.S. Department of Agriculture - Forest Service. (2018). Big Thorne Project . Retrieved from https://www.fs.usda.gov/detail/tongass/home/?cid=STELPRDB5425811

Weber, D., Hajek, A., \& Hoelmer, K. (2017). 1.1 Accidental Introductions of Natural Enemies: Causes and Implications. InProceedings of the 5th International Symposium on Biological Control of Arthropods (PG Mason, DR Gillespie, C Vincent (eds), pp. 2-6). Langkawi, Malaysia: CAB International.

Weckworth, B., Talbot, S., Sage, G., Person, D., \& Cook, J. (2005). A signal for independent coastal and continental histories among North American wolves. Molecular Ecology , 14 (4), 917-931.

Whiteley, A. R., Fitzpatrick, S. W., Funk, W. C., \& Tallmon, D. A. (2015). Genetic rescue to the rescue. Trends in Ecology 83 Evolution, 30 (1), 42-49.

Williams, B. W., Gilbert, J. H., \& Zollner, P. A. (2007).Historical Perspective on the Reintroduction of the Fisher and American Marten in Wisconsin and Michigan. US Department of Agriculture, Forest Service, Northern Research Station.

Wright, P. L. (1953). Intergradation between Martes americana andMartes caurina in Western Montana. Journal of Mammalogy ,34 (1), 74-86.

Zheng, X., Levine, D., Shen, J., Gogarten, S. M., Laurie, C., \& Weir, B. S. (2012). A high-performance computing toolset for relatedness and principal component analysis of SNP data. Bioinformatics ,28 (24), $3326-3328$.

\section{DATA ACCESSIBILITY}

Raw reads will be made available through NCBI's SRA upon manuscript acceptance (Accession number: \#\#\#\#\#). Custom python scripts are available at: https://github.com/jpcolella.

\section{AUTHOR CONTRIBUTIONS}

All authors conceived the project. JAC designed the project. JPC conducted bioinformatic analyses and wrote the first draft of the manuscript with scientific and editorial input from TL, SLT, JAC, and CL. TL designed bioinformatics pipeline and provided computational support. JAC collected and provided tissue 
samples through the Museum of Southwestern Biology. JAC and JPC funded genome sequencing. CL and JAC provided access to computational resources.

\section{TABLES \& FIGURES}

Figure 1. Range maps for M. americana (green) and M. caurina (blue) based on IUCN distributions (iucnredlist.org) and mitochondrial haplotype distributions (Dawson et al. 2017; Colella et al. 2018b) with hybrid zones (Kuiu and Kupreanof island and western Montana into southern British Columbia) denoted by gray hashing. Genome samples are indicated with points and 3-letter locality abbreviations that correspond to Table 1. Genome samples are colored based on ADMIXTURE K6 assignment (Fig. 3a): insular M. caurina (QCI, ADM), continental M. caurina (COL, PNW), continental (MAK, CHI*) and insular M. america$n a\left(\mathrm{POW}^{*}, \mathrm{REV}\right) .{ }^{*}$ indicates an island population that was received $M$. americanatranslocations from a mainland source population. Two hybrid individuals (KUI, MTX) are shown in grey with an X.

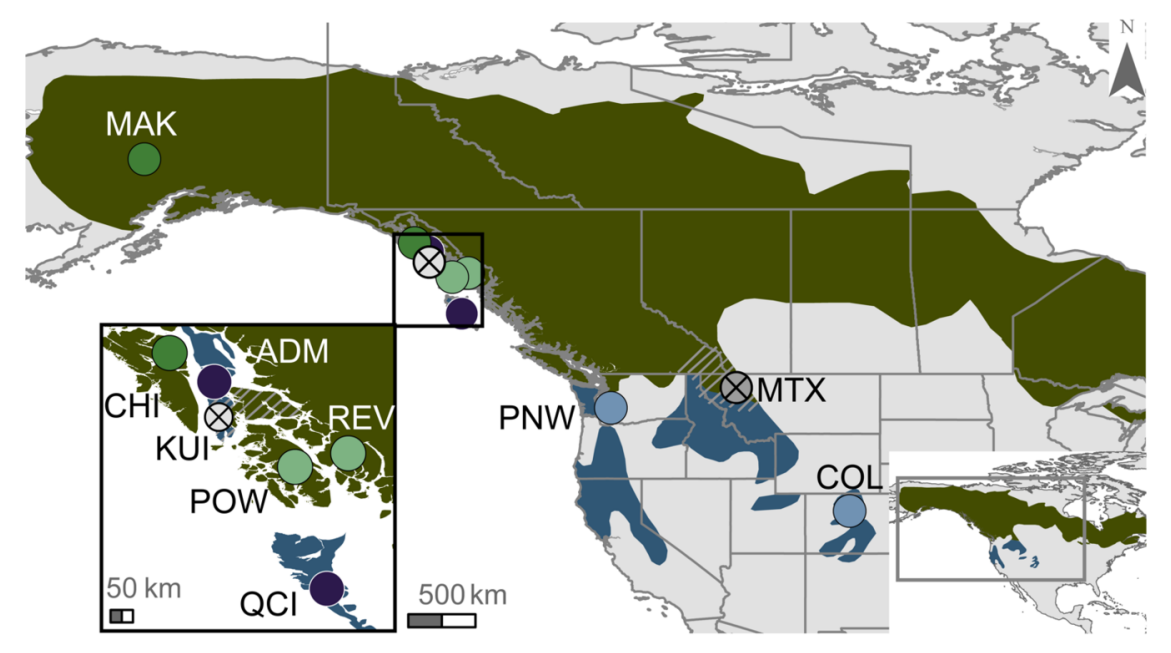

Figure 2. (a) Principal component analysis (PCA) of only $M$. americana samples; (b) All examined New World Martessamples, identifying 2 intermediate hybrids; and (c) PCA of $M$. caurina samples only, demonstrating significant differentiation between insular and continental populations (39\% of variation, PC1), and also between distinct continental populations of $M$. caurina (34\% of variation, PC2). (d) mirrored mitochondrial genome (mitogenome, left) and autosomal SNP (right) phylogenies, depicting 2 monophyletic marten species (M. americana green, M. caurina blue) and 2 unsorted, putative hybrids (MTX, KUI). Sample abbreviations are defined in Table 1. 


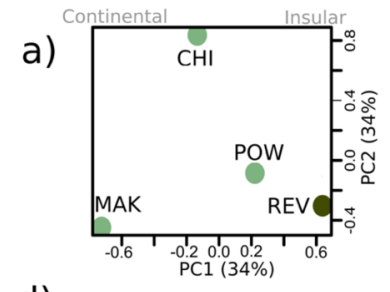

d)
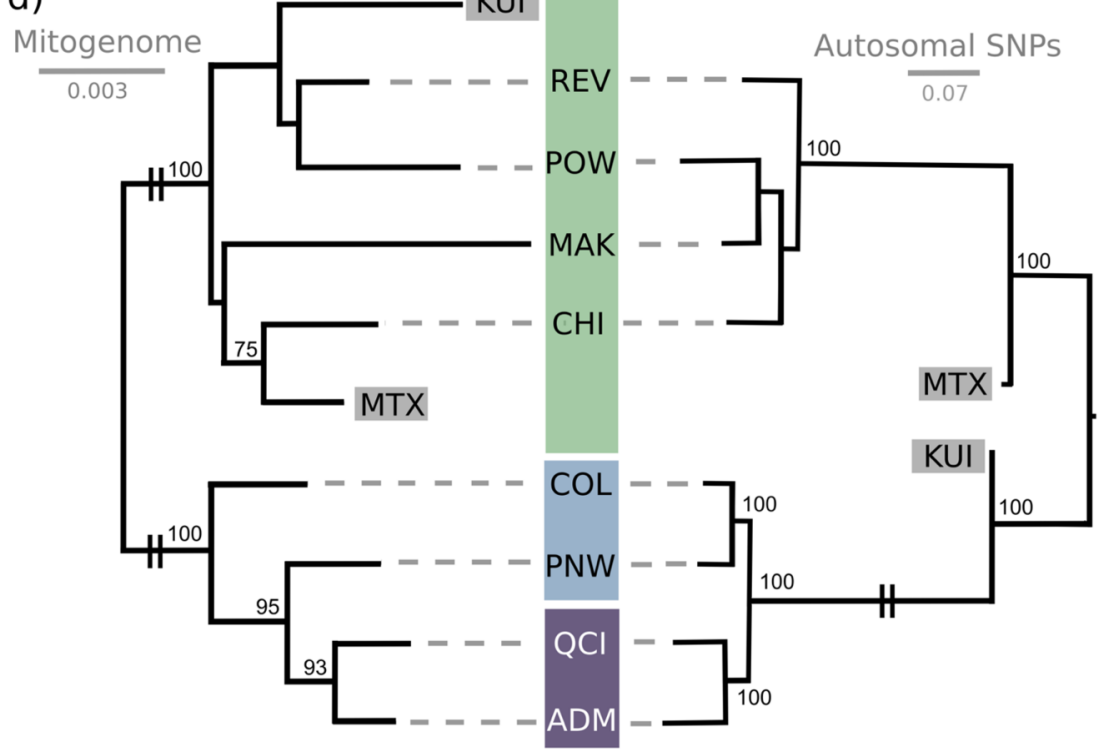

Figure 3. (a) Optimal ADMIXTURE population assignments (K6) and ancestry proportions for sampled New World Martes genomes, indicating 2 independent populations within each species (M. caurina blue and M. americana green) and two admixed individuals (KUI, MTX: gray; see also Supplemental Information 10). Specimen ID's correspond to abbreviations in Table 1; (b) PSMC distributions of historical demography for unadmixed samples scaled by a generation time of 5 years $(\mathrm{g})$ and general mammalian mutation rate $(\mathrm{mu}=$ $2.2 \times 10^{-9}$ ) demonstrating 3 distinct demographic trajectories: one for continental (C) M. caurina, one for insular (Is.) M. caurina, and one for M. americana. Colors correspond to the admixture plot in (a). 
a
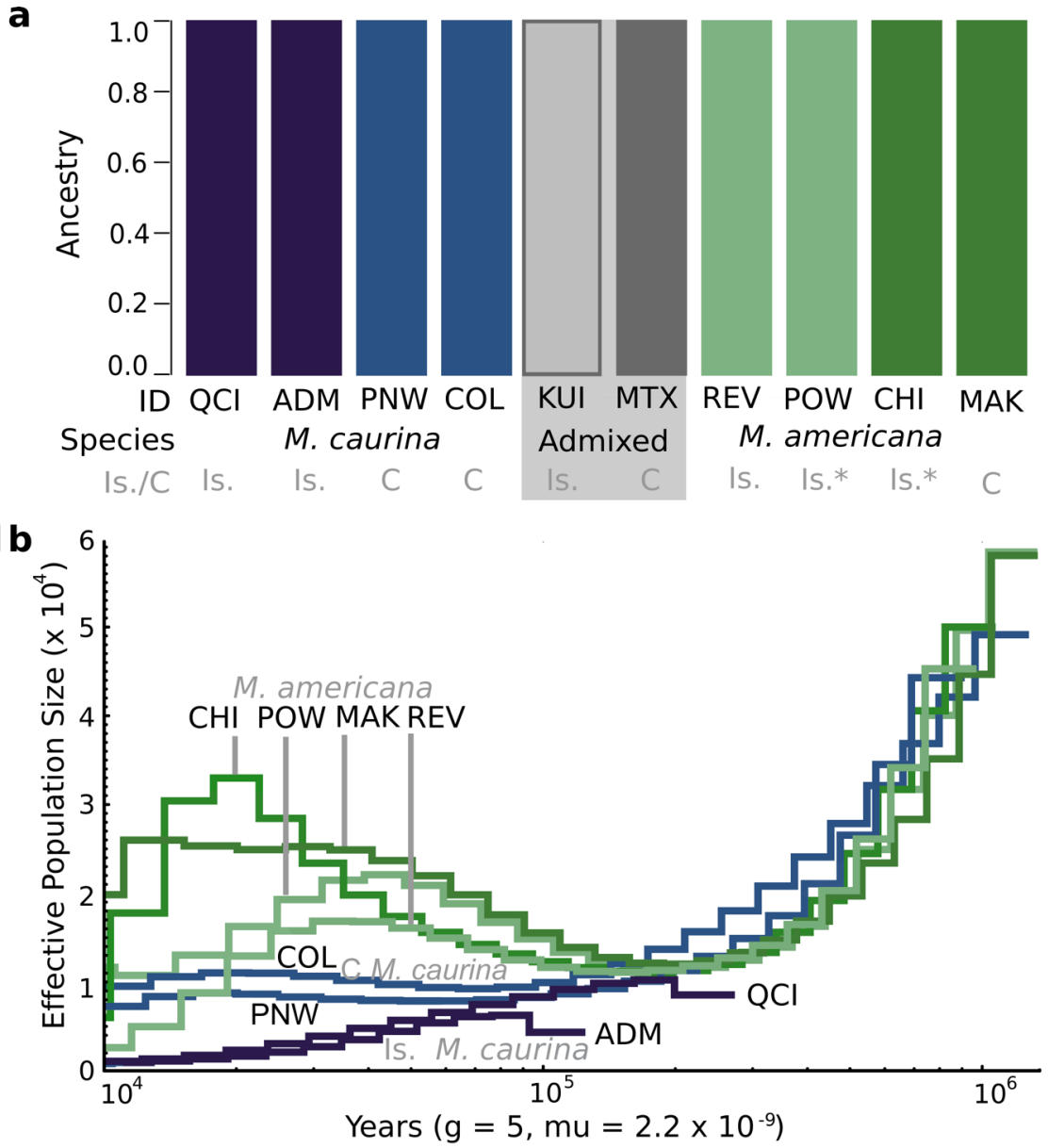

Figure 4. AdmixtureGraph results for each hybrid (KUI, MTX) based on F4 -statistics of populations identified by ADMIXTURE $(\mathrm{K}=6)$. Node abbreviations indicate: $\mathrm{CA}=$ coalescence between all $M$. caurina and $M$. americana, $\mathrm{CC}=$ coalescence between all $M$. caurina lineages, $\mathrm{AA}=$ coalescence between all $M$. americanalineages, CMX/CIX = coalescence between mainland/insular $M$. caurina and hybrids, AMX/AIX $=$ coalescence between mainland/insular $M$. americana and hybrids. OG = outgroup (Martes zibellina).
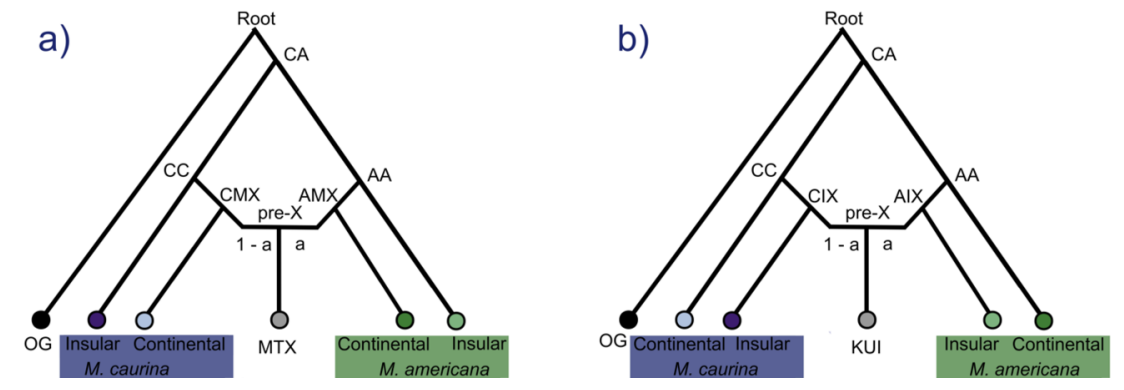

\section{TABLES}

Table 1. Museum specimen catalog numbers (ID), collection localities, and corresponding abbreviations (Abbrev.), species assignment, genomic coverage, and year of collection. MSB = Museum of Southwestern Biology (MSB:Mamm), UWBM = University of Washington (UWBM:Mamm), Burke Museum, UAM = 
University of Alaska Museum of the North (UAM:Mamm). IS = insular M. caurina clade, C = continental $M$. caurina clade

\begin{tabular}{lllllll}
\hline Museum ID & Abbrev. & Collection locality & Species & Coverage & Year Collected & Sequencing method \\
\hline MSB197660 & MAK & Central Alaska & M. americana & 22.52 & 2005 & NextSeq 500 \\
MSB221158 & POW & Prince of Wales Is. & M. americana & 19.89 & 2004 & HiSeq 10X \\
MSB34701 & CHI & Chichagof Is. & M. americana & 21.15 & 1994 & NextSeq 500 \\
MSB197227 & REV & Revillagigedo Is. & M. americana & 23.77 & 2003 & HiSeq 10X \\
UWBM81779 & PNW & Washington & M. caurina (C) & 30.33 & $<2010$ & HiSeq 10X \\
MSB224027 & COL & Colorado & M. caurina (C) & 28.19 & 2008 & NextSeq 500 \\
MSB197762 & ADM & Admiralty Is. & M. caurina (IS) & 21.15 & 2004 & NextSeq 500 \\
MSB157350 & QCI & Graham Is. & M. caurina (IS) & 24.46 & 2005 & HiSeq 10X \\
UAM69033 & MTX & Montana & admixed & 19.95 & 2004 & NextSeq 500 \\
UAM48762 & KUI & Kuiu Is. & admixed & 28.57 & 1997 & HiSeq 10X \\
MSB192919 & Mazi & Russia & M. zibellina & 28.65 & 2005 & HiSeq 10X \\
\hline
\end{tabular}

Table 2. Significantly ( $\mathrm{Z}$ score $[\mathrm{Z}]>5$ ) negative F3 statistics for both hybrids examined and associated source populations, group according to ADMIXTURE K6 results (Is.americana $=$ REV, POW; ML amer$i$ cana $=\mathrm{CHI}$, MAK; Is.caurina $=\mathrm{QCI}, \mathrm{ADM} ; \mathrm{ML}$ caurina $=\mathrm{PNW}, \mathrm{COL}-$ where Is. indicated island and ML indicated mainland or continental localities). SE $=$ standard error.

\begin{tabular}{lllllll}
\hline Target & Source2 & Source2 & F3 & SE & Z & SNPs \\
\hline KUI & Is. americana & Is. caurina & -0.341386 & 0.011619 & -29.382 & 36782 \\
KUI & ML americana & Is. caurina & -0.339249 & 0.01224 & -27.716 & 37150 \\
KUI & Is. americana & ML caurina & -0.32483 & 0.013937 & -23.306 & 38129 \\
KUI & ML americana & ML caurina & -0.322549 & 0.014368 & -22.449 & 38495 \\
MTX & ML americana & ML caurina & -0.304466 & 0.015845 & -19.215 & 35448 \\
MTX & ML americana & Is. caurina & -0.303897 & 0.015705 & -19.35 & 34614 \\
MTX & Is. americana & ML caurina & -0.298224 & 0.018026 & -16.545 & 35550 \\
MTX & Is. americana & Is. caurina & -0.297276 & 0.017801 & -16.7 & 34681 \\
\hline
\end{tabular}

